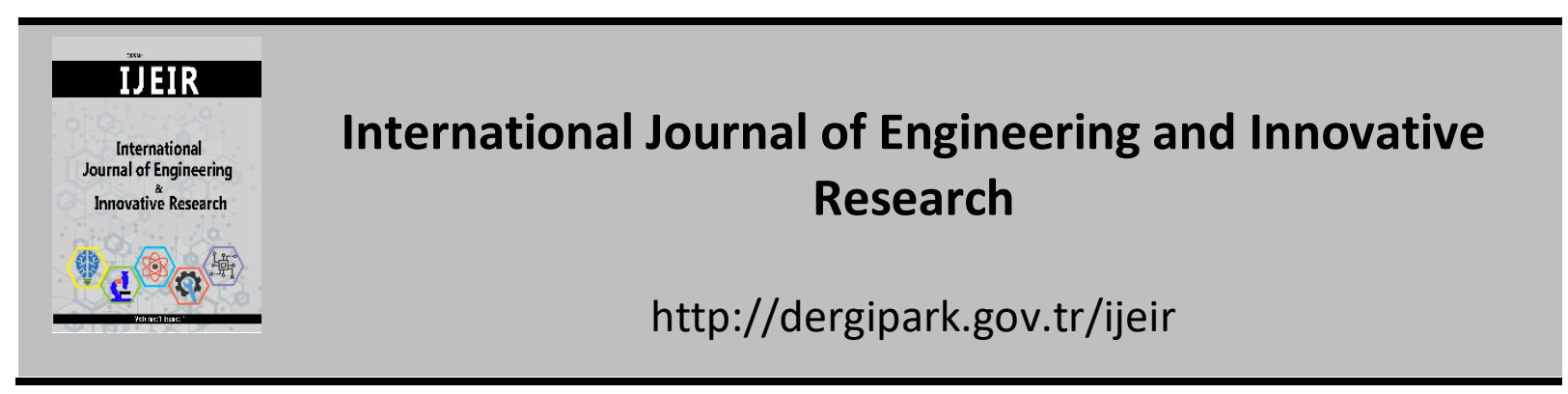

\title{
OPTIMISATION OF INJECTION MOULDED POLYPROPYLENE SAWDUST COMPOSITE USING RESPONSE SURFACE METHODOLOGY AND ARTIFICIAL NEURAL NETWORKS
}

\author{
Cyril Aliyegbenoma ${ }^{1 *} \mathbb{D}$, Mercy Ozakpolor ${ }^{1} \mathbb{C}$ \\ ${ }^{1}$ University of Benin, Department of Production Engineering, Benin City, Nigeria.
}

\section{https://doi.org/10.47933/ijeir.744495}

"Corresponding Author: cyril.aliyegbenoma@eng.uniben.edu

(Received: 28.05.2020; Revised: 03.06.2020; Accepted: 30.06.2020)

\begin{abstract}
This study focuses on the optimisation of the injection moulded Polypropylene -Sawdust composite. The Polypropylene material and sawdust were mixed together to form a homogenous mixture with various percentage composition by volume as recommended by the design of experiments using the central composite design (CCD). The two screw plunger injection moulding machine was used to produce PolypropyleneSawdust composite at various temperature. The produced composite was evaluated for its mechanical properties which included tensile strength, proof stress, percentage elongation and flexural strength. The response surface methodology (RSM) and artificial neural networks (ANN) were used to determine the effect of the interaction of temperature, material type and percentage by volume of material on the mechanical properties of the produced Polypropylene -sawdust composite. The models were validated using coefficient of determination $\left(\mathrm{R}^{2}\right)$, the coefficient of determination $\left(\mathrm{R}^{2}\right)$ obtained ranged from $0.9435(94.357 \%)$ to $0.9988(99.88 \%)$ which indicates that a substantial good fit was achieved by the developed models. A desirability of 0.952 was obtained which shows the adequacy of the model terms the optimization results for Polypropylene -Sawdust composite shows that the tensile strength, proof stress, flexural strength and flexural modulus were maximized with a values of $31.90 \mathrm{MPa}$, 41.94 MPa, 88.22 MPa and 2.72 GPa respectively which was obtained at barrel temperature of $224.65{ }^{\circ} \mathrm{C}$. Percentage elongation and average deflection were minimized with a values of $74.12 \%$ and $6.46 \mathrm{~cm}$ respectively. The artificial neural networks gave the optimal of the two examined models.
\end{abstract}

Keywords: Central composite design, Composite, Modeling, Polypropylene, Sawdust.

\section{INTRODUCTION}

Injection moulding is a very complex process and its process variable like barrel temperature, injection pressure, the material flow rate, mould temperature and flow pattern usually influence the properties of polymeric materials [1]. Injection moulding is a cost-effective way to produce complex, three dimensional shapes at high volumes. In the plastic industry, injection moulding makes up about $32 \%$ weight of all plastic processing methods, this is second only to extrusion which is $36 \%$ weight. Composite are man-made materials which are currently being used in wide application in the manufacture of industrial as well as consumer products [2].The deformable state achieved by plastic-sawdust composites at elevated temperature before chemically setting, allow them to be shaped to any intricate form. According to this principle of combined action; new properties, better property combinations, or a higher level of properties are fashioned by the judicious combination of two or more distinct materials. A typical composite material is a system of materials comprising two or more materials (mixed and bonded) on a macroscopic scale. 
Investigation was carried out to model the fundamental bonding characteristics and performance of wood composite [3]. In this investigation, a mathematical model and a computer simulation model were developed to predict the variation of inter-element (strand) contact during mat consolidation. The mathematical predictions and the computer simulations agree well with each other. Their results showed that the relationship between the inter-element contact and the mat density was highly nonlinear and was significantly affected by the wood density and the element thickness.

Moreover, empirical models were developed making use of previously obtained experimental data to estimate the properties of produced composite material from agro waste. The developed empirical models were used to predict the properties of composite material (hardness, yield strength, ultimate tensile strength, modulus of elasticity, modulus of rupture, internal bond strength, density, thickness of swelling and water absorption) taking the inputs as percentage of sawdust composition and percentage of palm shell composition respectively [4].

The effect of reinforcement combination on the mechanical strength of glass reinforced plastic was examined using compression moulding. A Proof stress of $29.52 \mathrm{~N} / \mathrm{mm}^{2}$ at a barrel temperature of $232^{\circ} \mathrm{C}$ was obtained [5]. The effects of temperature relative humidity and feedstock temperature on injection moulded part dimension and short term mechanical properties observed from tensile testing was investigated and results indicated that environmental conditions influenced the moulded part quality to varying degrees and that the environmental conditions should be controlled for applications with tight tolerances [6].

Injection modelled polypropylene sawdust composite produced and some mechanical properties like, tensile strength, proof stress, percentage elongation, average deflection, flexural modulus and flexural strength were determined [7].

This study therefore seek to optimize the produced polypropylene-sawdust composite in order to determine the optimal composition of the input parameters.

\section{MATERIALS AND METHODS}

The following materials were used for this work: Polypropylene (PP) in powdered form, Sawdust (from Mahogany tree obtained from saw mill in Benin City, Edo State Nigeria, two stage-screw plunger Injection machine (Fox and offord), 120 tons two stage-screw plunger, a toggle clamp attached to the injection end of injection moulding, MONSANTO TENSOMETER, Type 'W' Serial No. 8991 and a mould made from Silicon.

\subsection{Method of Data Collection}

In this study, primary data were collected from the mechanical properties test results obtained from the developed Polypropylene-Sawdust composite.

\subsection{Experimental Designs}

In this study, a two-variable central composite design (CCD) was used to plan the experiments, develop statistical models for predicting the chosen responses and to optimise the responses and factors. The design points are made up of $2 \mathrm{n}$ factorial points as well as star points. The star points are particularly necessary for estimating the curvature of the response surface especially 
for nonlinear models. The CCD is the only response surface design that can be used for planning experiments with two factors [8].

\subsection{Models Development}

Design Expert ${ }^{\circledR}$ software version 7.0.0, (Stat-ease, Inc. Minneapolis, USA) was used to design the experiment and to analyze the experimental data obtained. The factors considered were temperature and the level of polymer (PP) in the matrix. The range and levels of these factors are shown in Table 2 and was calculated using Equation (1). In generating the experimental design matrix, the Design Expert ${ }^{\circledR}$ software utilizes the concept of randomisation and the essence of this is to minimise the effect of unexplained variability in the chosen responses [9]. In this case, the responses chosen for consideration were tensile strength, proof stress, percentage elongation, average deflection, flexural strength and flexural modulus.

$x_{i}=\frac{X_{i}-X_{o}}{\Delta X_{i}}$

In Equation 1, $x_{i}$ and $X_{i}$ are the coded and actual values of the factors respectively while $X_{o}$ is the actual value of the factors at the centre point, and $\Delta X_{i}$ is the step change in the value of the actual values of the factors.

In selecting the appropriate model for predicting the responses, different model types in the Design Expert software library were considered. The first type of model usually investigated is a linear model shown in Equation (2). It is usually proposed to predict the response of the dependent variables and to predict their optimum values when the relationship between the factors and the responses is thought to be linear.

$$
Y=b_{o}+\sum_{i=1}^{N} b_{i} X_{i}+\sum_{i=1}^{N} e_{i}
$$

Where $Y_{i}$ is the dependent variable or predicted response, $X_{i}$ is the independent variables, $b_{o}$ is offset term, $b_{i}$ is the regression coefficient and $e_{i}$ is the error term.

Equation (3) is a two-factor interaction regression model which was also proposed to predict the response of the dependent variables and to predict their optimum values.

$$
Y=b_{o}+\sum_{i=1}^{N} b_{i} X_{i}+\sum_{i, j=1}^{N} b_{i j} X_{i} X_{j}+\sum_{i=1}^{N} e_{i}
$$

$X_{j}$ is the independent variables or factors while $b_{i j}$ is the coefficient of the interaction terms. For situations where the relationship between the factors and the responses is thought to be nonlinear, a second order model as shown in Equation 4 can be used to predict the response.

$$
Y=b_{o}+\sum_{i=1}^{N} b_{i} X_{i}+\sum_{i, j=1}^{N} b_{i j} X_{i} X_{j}+\sum_{i=1}^{N} b_{i i} X_{i}^{2}+\sum_{i=1}^{N} e_{i}
$$

The second order model is the most widely used model for response surface methodology [9]. 
Table 1. $\mathrm{R}^{2}$ and RMSE Values of MNFF and MFFF using Different Training Algorithms for Flexural Strength (PP-sawdust composite).

\begin{tabular}{|c|c|c|c|c|c|c|c|}
\hline $\begin{array}{c}\text { Network } \\
\text { architecture }\end{array}$ & $\begin{array}{c}\text { Training } \\
\text { algorithm }\end{array}$ & $\mathrm{R}$ squared & RMSE & $\begin{array}{c}\text { Network } \\
\text { architecture }\end{array}$ & $\begin{array}{c}\text { Training } \\
\text { algorithm }\end{array}$ & $\mathrm{R}$ squared & RMSE \\
\hline \multirow{5}{*}{$* \mathrm{MNFF}$} & *IBP & 0.9987 & 0.2359 & \multirow{5}{*}{ MFFF } & IBP & 0.9971 & 0.3567 \\
\hline & BBP & 0.9976 & 0.3245 & & BBP & 0.9975 & 0.3263 \\
\hline & $\mathrm{QP}$ & 0.9749 & 1.0416 & & $\mathrm{QP}$ & 0.9705 & 1.1288 \\
\hline & GA & 0.9968 & 0.3708 & & GA & 0.9969 & 0.3636 \\
\hline & LM & 0.3603 & 5.2583 & & LM & 0.9221 & 1.8351 \\
\hline
\end{tabular}

*best learning algorithm and network

\section{RESULTS AND DISCUSSION}

The range and levels of these factors are shown in Table 2 and they were calculated using Equation.1 [10]. In this case, the responses chosen for consideration were tensile strength, proof stress, percentage elongation, average deflection, flexural strength and flexural modulus.

Table 2. Coded and Actual Levels of the Factors for PP-Sawdust Composite.

\begin{tabular}{|c|c|c|c|c|c|c|c|}
\hline \multirow{2}{*}{ Factors } & \multirow{2}{*}{ Unit } & \multirow{2}{*}{ Symbols } & \multicolumn{5}{|c|}{ Coded and Actual Levels } \\
\cline { 4 - 8 } & & & -1.414 & -1 & 0 & 1 & 1.414 \\
\hline Temperature & ${ }^{\circ} \mathrm{C}$ & $\mathrm{X}_{1}$ & 210.00 & 224.64 & 260.00 & 295.36 & 310.00 \\
\hline PVC level & $\%$ & $\mathrm{X}_{2}$ & 60.00 & 61.46 & 65.00 & 68.54 & 70.00 \\
\hline
\end{tabular}

\subsection{Determination of Appropriate Model}

Table 3 shows the summary of model fit results for PP-Sawdust composite

Table 3. Summary of Model Fit Results (PP-Sawdust Composite).

\begin{tabular}{|c|c|c|c|c|c|c|}
\hline \multicolumn{7}{|c|}{ Tensile strength } \\
\hline Source & $\begin{array}{l}\text { Standard } \\
\text { deviation }\end{array}$ & $\mathrm{R}^{2}$ & $\begin{array}{c}\text { Adjusted } \\
\mathrm{R}^{2}\end{array}$ & $\begin{array}{l}\text { Predicted } \\
\mathrm{R}^{2}\end{array}$ & PRESS & Remark \\
\hline Linear & 4.06 & 0.0289 & 0.0165 & 0.0161 & 323.34 & \\
\hline $2 \mathrm{FI}$ & 4.28 & 0.0289 & 0.0249 & 0.0152 & 429.50 & \\
\hline Quadratic & 1.86 & 0.8579 & 0.7564 & 0.0470 & 170.83 & Suggested \\
\hline Cubic & 0.66 & 0.9872 & 0.9692 & 0.2456 & 128.28 & Aliased \\
\hline \multicolumn{7}{|c|}{ Proof stress } \\
\hline Source & $\begin{array}{l}\text { Standard } \\
\text { deviation }\end{array}$ & $\mathrm{R}^{2}$ & $\begin{array}{c}\text { Adjusted } \\
\mathrm{R}^{2}\end{array}$ & $\begin{array}{c}\text { Predicted } \\
\mathrm{R}^{2}\end{array}$ & PRESS & Remark \\
\hline Linear & 4.04 & 0.0339 & 0.01593 & 0.008 & 318.57 & \\
\hline $2 \mathrm{FI}$ & 4.25 & 0.0339 & 0.0288 & 0.0152 & 426.14 & \\
\hline Quadratic & 1.83 & 0.8614 & 0.7625 & 0.0268 & 164.08 & Suggested \\
\hline Cubic & 0.78 & 0.9821 & 0.9571 & 0.7404 & 169.85 & Aliased \\
\hline
\end{tabular}


Table 4. Lack of Fit Test Results (PP-Sawdust composite).

\begin{tabular}{|c|c|c|c|c|c|c|}
\hline \multicolumn{7}{|c|}{ Tensile strength } \\
\hline Source & $\begin{array}{c}\text { Sum of } \\
\text { square }\end{array}$ & $\begin{array}{c}\text { Degree of } \\
\text { freedom }\end{array}$ & $\begin{array}{c}\text { Mean } \\
\text { square }\end{array}$ & F-value & p-value & Remark \\
\hline Linear & 164.95 & 6 & 27.49 & 610.93 & $<0.0001$ & \\
\hline 2FI & 164.95 & 5 & 32.99 & 733.10 & $<0.0001$ & \\
\hline Quadratic & 23.98 & 3 & 7.99 & 177.65 & 0.081 & Suggested \\
\hline Cubic & 2.00 & 1 & 2.00 & 44.44 & 0.0026 & Aliased \\
\hline Pure Error & 0.18 & 4 & 0.045 & & & \\
\hline \multicolumn{7}{|c|}{ Proof stress } \\
\hline Source & Sum of & degree of & Mean & F-value & p-value & Remark \\
\hline Linear & 162.52 & 6 & 27.09 & 294.43 & $<0.0001$ & \\
\hline 2FI & 162.52 & 5 & 32.50 & 353.31 & $<0.0001$ & \\
\hline Quadratic & 22.99 & 3 & 7.66 & 83.31 & 0.0510 & Suggested \\
\hline Cubic & 2.64 & 1 & 2.64 & 28.75 & 0.0058 & Aliased \\
\hline Pure Error & 0.37 & 4 & 0.092 & & & \\
\hline Alyegbed & square & & \\
\end{tabular}

Source: Aliyegbenoma et al 2020

Tables 3 and 4 shows the Summary of model fit results and Lack of fit test results for PPSawdust composite respectively. As seen from the results, the quadratic model was suggested as the most appropriate model to predict the responses. This decision was reached based on the statistical parameters backing up the quadratic model. Among a number of alternatives, the model chosen should be the one with the desirable statistical parameters such as high $\mathrm{R}^{2}$ value, low standard deviation, and low PRESS. The quadratic model was found to have the highest $\mathrm{R}^{2}$ values for all the responses for tensile strength and proof stress as shown in Table 3 for PPSawdust composite. The quadratic model was also found to have the lowest standard deviation and PRESS as shown in Table 4 for PP-Sawdust composite. Thus, the quadratic model was adopted for predicting the responses under investigation in this study.

Table 5 shows the RSM predicted result and the experimental for tensile strength and proof stress for PP-Sawdust composite, while table 6 shows the ANN predicted and experimental results for tensile strength and proof stress for PP-Sawdust composite.

Table 5. Experimental and RSM Predicted Results for Tensile Strength and Proof Stress (PP-Sawdust Composite).

\begin{tabular}{|c|c|c|c|c|c|c|c|c|}
\hline \multirow{2}{*}{ Run } & \multicolumn{4}{|c|}{ Factors } & \multicolumn{4}{c|}{ Response } \\
\cline { 2 - 9 } & \multicolumn{2}{|c|}{ Coded values } & \multicolumn{2}{|c|}{ Actual values } & \multicolumn{2}{c|}{ Tensile strength (MPa) } & \multicolumn{2}{c|}{ Proof stress } \\
\cline { 2 - 9 } & $\mathrm{X}_{1}$ & $\mathrm{X}_{2}$ & $\mathrm{X}_{1}$ & $\mathrm{X}_{2}$ & Experiment & Predicted & Experiment & Predicted \\
\hline 1 & 0 & 0 & 260.00 & 50.00 & 33.70 & 33.50 & 43.60 & 43.48 \\
\hline 2 & 1 & -1 & 295.36 & 42.93 & 28.60 & 29.23 & 39.60 & 40.17 \\
\hline 3 & 1 & 1 & 295.36 & 57.07 & 29.40 & 28.87 & 39.10 & 38.64 \\
\hline 4 & 1.414 & 0 & 310.00 & 50.00 & 33.80 & 33.77 & 43.80 & 43.80 \\
\hline 5 & 0 & -1.414 & 260.00 & 40.00 & 25.50 & 24.60 & 36.60 & 35.68 \\
\hline 6 & 0 & 1.414 & 260.00 & 60.00 & 23.30 & 24.03 & 33.70 & 34.23 \\
\hline
\end{tabular}




\begin{tabular}{|c|c|c|c|c|c|c|c|c|}
\hline 7 & -1 & -1 & 224.64 & 42.93 & 28.50 & 29.20 & 38.60 & 39.46 \\
\hline 8 & -1.414 & 0 & 210.00 & 50.00 & 33.80 & 33.66 & 43.90 & 43.50 \\
\hline 9 & -1 & 1 & 224.64 & 57.07 & 29.20 & 28.75 & 39.10 & 38.93 \\
\hline 10 & 0 & 0 & 260.00 & 50.00 & 33.70 & 33.50 & 43.30 & 43.48 \\
\hline 11 & 0 & 0 & 260.00 & 50.00 & 33.50 & 33.50 & 43.10 & 43.48 \\
\hline 12 & 0 & 0 & 260.00 & 50.00 & 33.20 & 33.50 & 43.50 & 43.48 \\
\hline 13 & 0 & 0 & 260.00 & 50.00 & 33.40 & 33.50 & 43.90 & 43.48 \\
\hline
\end{tabular}

Table 6. Experimental and ANN Predicted Results for Tensile Strength and Proof Stress (PP-Sawdust Composite).

\begin{tabular}{|c|c|c|c|c|c|c|c|c|}
\hline \multirow{3}{*}{ Run } & \multicolumn{5}{|c|}{ Factors } & \multicolumn{4}{c|}{ Response } \\
\cline { 2 - 9 } & \multicolumn{2}{|c|}{ Coded values } & \multicolumn{2}{|c|}{ Actual values } & \multicolumn{2}{c|}{ Tensile strength (MPa) } & \multicolumn{2}{c|}{ Proof stress } \\
\cline { 2 - 9 } & $\mathrm{X}_{1}$ & $\mathrm{X}_{2}$ & $\mathrm{X}_{1}$ & $\mathrm{X}_{2}$ & Experiment & Predicted & Experiment & Predicted \\
\hline 1 & 0 & 0 & 260.00 & 50.00 & 33.70 & 33.50 & 43.60 & 43.48 \\
\hline 2 & 1 & -1 & 295.36 & 42.93 & 28.60 & 28.60 & 39.60 & 39.60 \\
\hline 3 & 1 & 1 & 295.36 & 57.07 & 29.40 & 29.40 & 39.10 & 39.10 \\
\hline 4 & 1.414 & 0 & 310.00 & 50.00 & 33.80 & 33.80 & 43.80 & 43.80 \\
\hline 5 & 0 & -1.414 & 260.00 & 40.00 & 25.50 & 25.50 & 36.60 & 36.60 \\
\hline 6 & 0 & 1.414 & 260.00 & 60.00 & 23.30 & 23.30 & 33.70 & 33.70 \\
\hline 7 & -1 & -1 & 224.64 & 42.93 & 28.50 & 28.50 & 38.60 & 38.60 \\
\hline 8 & -1.414 & 0 & 210.00 & 50.00 & 33.80 & 33.80 & 43.90 & 43.90 \\
\hline 9 & -1 & 1 & 224.64 & 57.07 & 29.20 & 29.20 & 39.10 & 39.10 \\
\hline 10 & 0 & 0 & 260.00 & 50.00 & 33.70 & 33.50 & 43.30 & 43.48 \\
\hline 11 & 0 & 0 & 260.00 & 50.00 & 33.50 & 33.50 & 43.10 & 43.48 \\
\hline 12 & 0 & 0 & 260.00 & 50.00 & 33.20 & 33.50 & 43.50 & 43.48 \\
\hline 13 & 0 & 0 & 260.00 & 50.00 & 33.40 & 33.50 & 43.90 & 43.48 \\
\hline
\end{tabular}

\subsection{Comparison of RSM and ANN Predictive Performance}

In order to determine the optimal parameters and the accuracy of RSM and ANN in predicting tensile strength, proof stress, percentage elongation, average deflection, flexural strength and flexural modulus, the comparison is directly related to their predictive capability. The model with the better predictive capability will be able to predict the responses with a higher accuracy. The predictive capability of RSM and ANN was assessed using $\mathrm{R}^{2}$ value, adjusted $\mathrm{R}^{2}$ value, root mean square error (RMSE) and absolute average deviation (AAD) as shown in Table 7 for PP-Sawdust composite. A good and accurate model prediction is usually characterized by high values of the $\mathrm{R}^{2}$ value and adjusted $\mathrm{R}^{2}$ value as well as very low RMSE and AAD. A comparison of the predictive capability of RSM and ANN as observed from the $\mathrm{R}^{2}$ value, adjusted $\mathrm{R}^{2}$ value, root mean square error and absolute average deviation shows that ANN performed better than RSM. This is because ANN had a very high $R^{2}$ and adjusted $R^{2}$ values with a very low RMSE and AAD values compared with RSM as shown in Table 7.

Table 7. Comparison of RSM and ANN Predictive Performance (PP-Sawdust Composite).

\begin{tabular}{|c|c|c|c|c|c|c|c|c|c|c|c|c|}
\hline \multirow[b]{2}{*}{$\begin{array}{c}\text { Parameter } \\
\mathrm{s}\end{array}$} & \multicolumn{6}{|c|}{ RSM } & \multicolumn{6}{|c|}{ ANN } \\
\hline & $\begin{array}{c}\text { Tensile } \\
\text { strengt } \\
\mathrm{h}\end{array}$ & $\begin{array}{l}\text { Pro. } \\
\text { Stress }\end{array}$ & $\begin{array}{c}\% \\
\text { elongatio } \\
\mathrm{n}\end{array}$ & $\begin{array}{c}\text { Aver. } \\
\text { deflectio } \\
\mathrm{n}\end{array}$ & $\begin{array}{c}\text { Flexura } \\
1 \\
\text { strength }\end{array}$ & $\begin{array}{c}\text { Flexural } \\
\text { modulu } \\
\mathrm{s}\end{array}$ & $\begin{array}{c}\text { Tensile } \\
\text { strengt } \\
\mathrm{h}\end{array}$ & $\begin{array}{c}\text { Pro. } \\
\text { stress }\end{array}$ & $\begin{array}{c}\% \\
\text { elongatio } \\
\mathrm{n}\end{array}$ & $\begin{array}{c}\text { Aver. } \\
\text { deflectio } \\
\mathrm{n}\end{array}$ & $\begin{array}{c}\text { Flexura } \\
1 \\
\text { strength }\end{array}$ & $\begin{array}{c}\text { Flexural } \\
\text { modulu } \\
\mathrm{s}\end{array}$ \\
\hline $\mathrm{R}^{2}$ & 0.9810 & $\begin{array}{c}0.978 \\
1\end{array}$ & 0.9791 & 0.8834 & 0.9887 & 0.8965 & 0.9988 & $\begin{array}{c}0.997 \\
3\end{array}$ & 0.9957 & 0.9709 & 0.9987 & 0.9435 \\
\hline Adj. $\mathrm{R}^{2}$ & 0.9675 & $\begin{array}{c}0.962 \\
5\end{array}$ & 0.9641 & 0.8000 & 0.9807 & 0.8226 & 0.9979 & $\begin{array}{c}0.995 \\
4\end{array}$ & 0.9926 & 0.9501 & 0.9978 & 0.9031 \\
\hline
\end{tabular}




\begin{tabular}{|c|c|c|c|c|c|c|c|c|c|c|c|c|}
\hline RMSE & 0.3817 & $\begin{array}{c}0.384 \\
7\end{array}$ & 0.6077 & 0.2655 & 0.5404 & 0.0699 & $\mathbf{0 . 0 9 4 9}$ & $\mathbf{0 . 1 3 5}$ & $\mathbf{0 . 2 7 7 5}$ & $\mathbf{0 . 1 3 2 8}$ & $\mathbf{0 . 1 8 2 8}$ & $\mathbf{0 . 0 5 1 9}$ \\
\hline AAD & 0.0088 & $\begin{array}{c}0.006 \\
4\end{array}$ & 0.0055 & 0.0265 & 0.0044 & 0.0189 & $\mathbf{0 . 0 0 1 2}$ & $\mathbf{0 . 0 0 1}$ & $\mathbf{0 . 0 0 1 6}$ & $\mathbf{0 . 0 0 8 1}$ & $\mathbf{0 . 0 0 1 0}$ & $\mathbf{0 . 0 0 8 3}$ \\
\hline
\end{tabular}

\subsection{Polarity Plot for RSM and ANN}

Figures1 (a) and (b) show the ANN parity plot of the responses for PP sawdust composites. It is a plot of the predicted response values versus the experimental response values. The purpose is to detect a value, or group of values, that are not easily predicted by the model. Comparison of the experimental values of the response and those predicted by the ANN model showed that there was an acceptable level of fit between the experimental and model predicted results. This is evident from the fact that the data points all clustered around the $45^{\circ}$ diagonal line showing that there was minimal deviation between experimental and predicted values thus indicating optimal fit of the model. Comparing these results with those presented in Figures 1(c) and (d) for the RSM prediction, it can be seen that the data points in Figures 1 (a) and (b) clustered around the $45^{\circ}$ diagonal line closer than that for the RSM results. This is an indication that the ANN model has better predictive capability compared to the RSM model. Therefore the optimal composition model is shown in Equation 5.

PP sawdust composite $=45.56 X_{2}+54.44 X_{3}$ at temp of $224.64{ }^{\circ} \mathrm{C}$
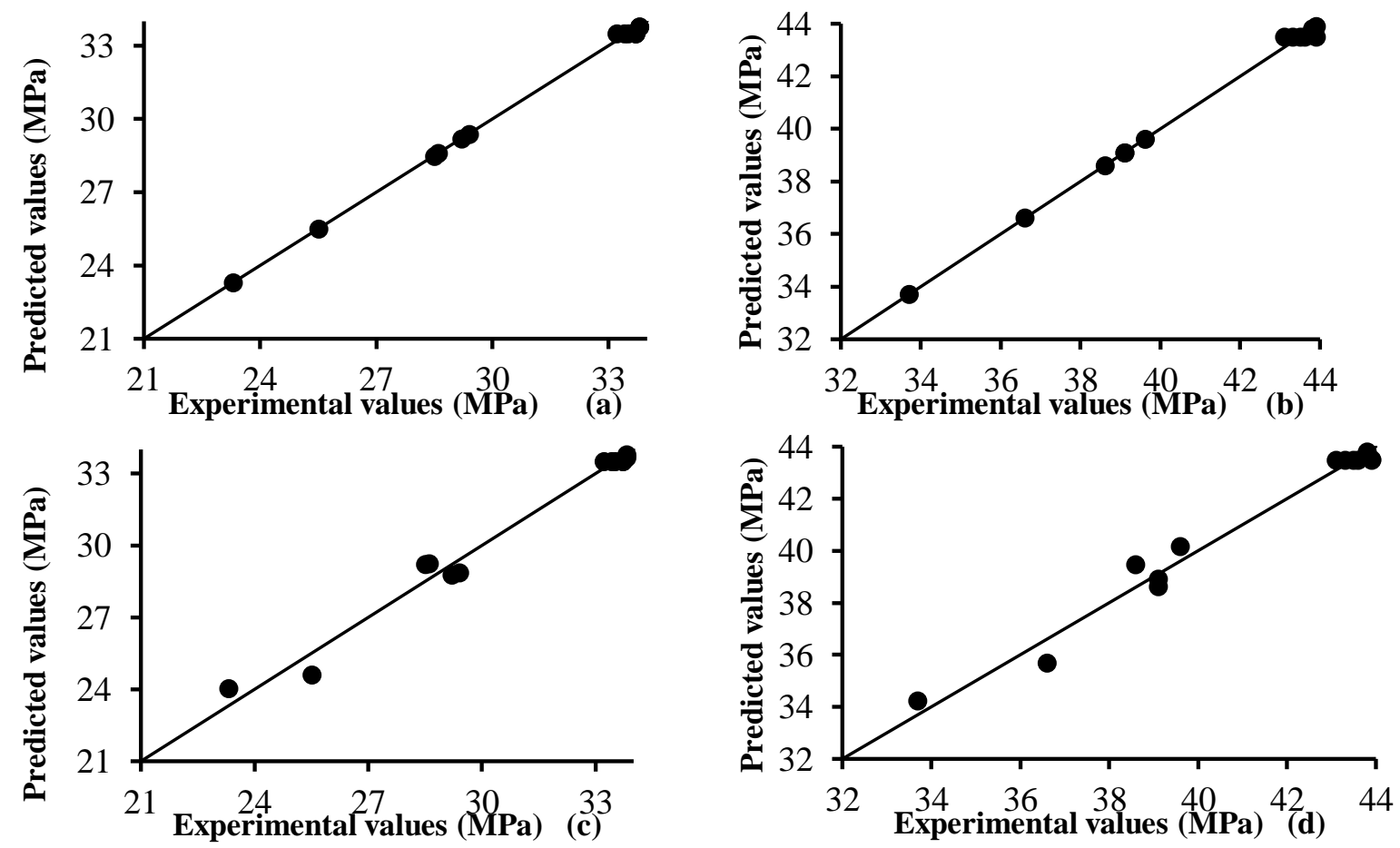

Figure 1. (a) Tensile strength (b) proof stress for ANN parity plot and (c) tensile strength (d) proof stress for RSM parity plot for PP-Sawdust composite.

\subsection{Optimal Composition for PP-Sawdust Composite}

Table 8 shows the variables and their optimal values for PP-sawdust composite.

Table 8. Optimization result for PP-sawdust composite 


\begin{tabular}{|l|l|}
\hline \multicolumn{1}{|c|}{ Variable } & \multicolumn{1}{c|}{ Value } \\
\hline Temperature & $224.64{ }^{\circ} \mathrm{C}$ \\
\hline Polymer level & $45.56 \%$ \\
\hline Maximum tensile strength & $31.90 \mathrm{Mpa}$ \\
\hline Maximum proof stress & $41.94 \mathrm{Mpa}$ \\
\hline Minimum percentage & $74.12 \%$ \\
\hline Minimum average & $6.46 \mathrm{~cm}$ \\
\hline Maximum flexural strength & $88.22 \mathrm{Mpa}$ \\
\hline Maximum flexural & $2.72 \mathrm{Gpa}$ \\
\hline Desirability & 0.952 \\
\hline
\end{tabular}

\subsection{Response Surface and Contour Plot}

Figure 2 shows the response surface and contour plot showing the effect of temperature and polymer level on (a) tensile strength (b) proof stress for the PP-sawdust composite. Intermediate levels of PP-sawdust were necessary to achieve optimum values of tensile strength as shown in Figure 2 (a). On the other hand, the effect of temperature on tensile strength was not very significant. For proof stress, Figure 2 (b) shows a similar trend to that shown in Figure 2(a). In the same way, intermediate levels of PP-sawdust were necessary to achieve optimum values of proof stress while temperature did not significantly influence the value of proof stress.
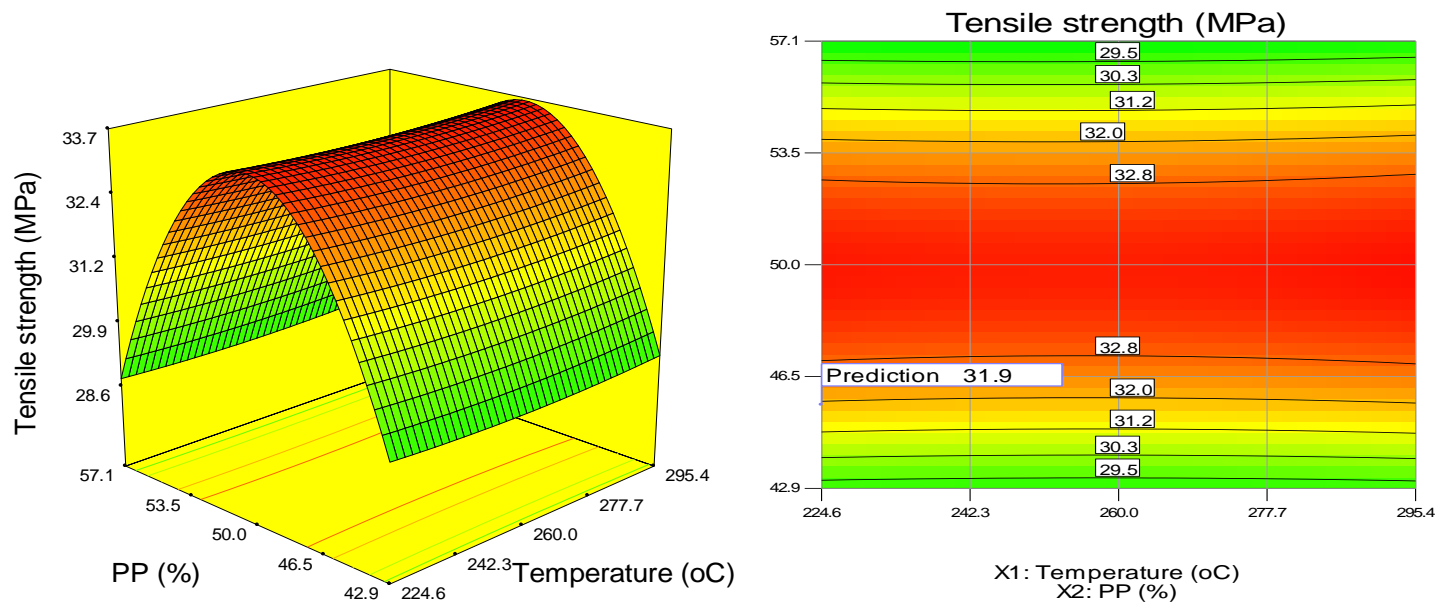

(a)
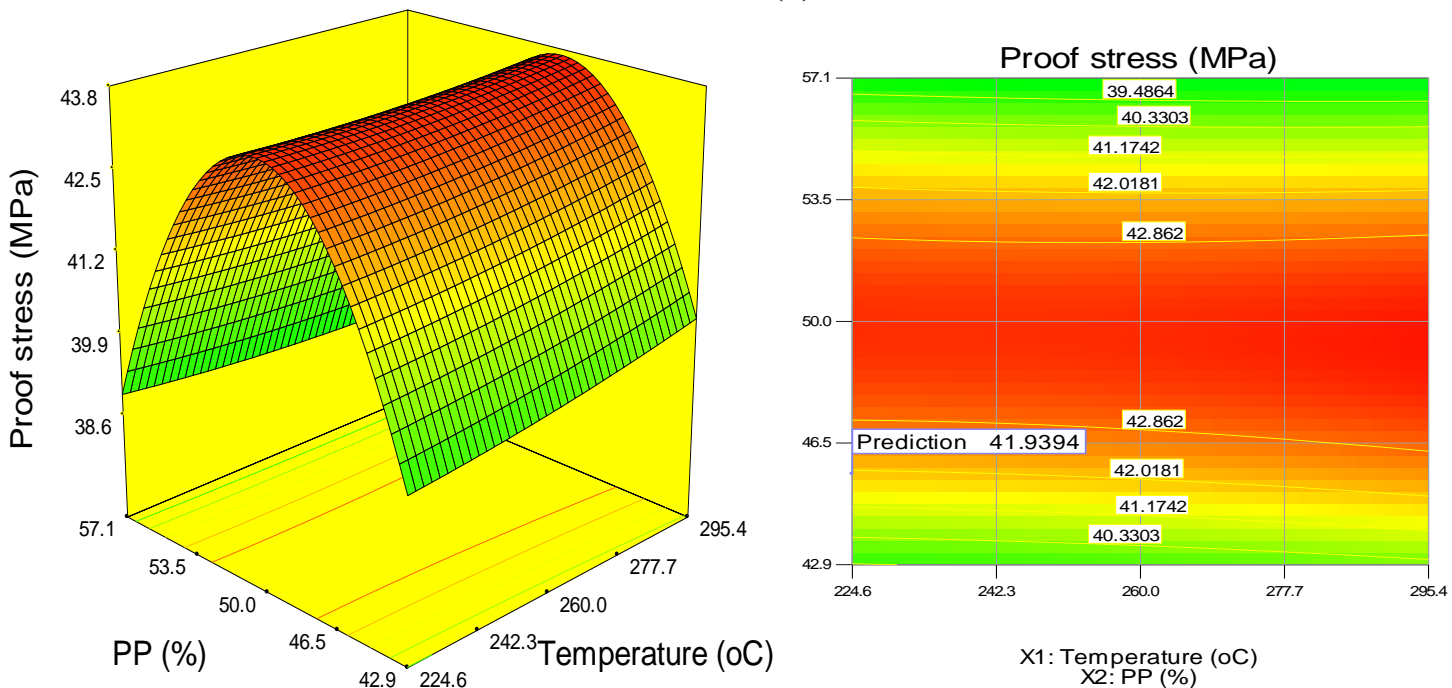

(b)

Figure 2. Response surface and contour plot showing effect of temperature and polymer level on (a) tensile strength (b) proof stress for PP-Sawdust composite. 


\section{CONCLUSION}

Models were developed for predicting the optimal mechanical properties (tensile strength, proof stress, percentage elongation and flexural strength) for the produced Polypropylene-sawdust composites with a desirability of 0.952 . in validating the model coefficient of determination $(\mathrm{R} Z)$ was used which gave a range of values between 0.9135 and 0.9988 which is an indication of achieving sustantial good fit by the developed model. Also from the result of the R2, adjusted $\mathrm{R}^{2}$, RMSE and ADD.

The optimization results for Polypropylene-sawdust composite shows that the tensile strength, proof stress, flexural strength and flexural modulus were maximized with values of $31.90 \mathrm{MPa}$, $41.94 \mathrm{MPa}, 88.22 \mathrm{MPa}$ and $2.72 \mathrm{GPa}$ respectively obtained at barrel temperature of $224.65{ }^{\circ} \mathrm{C}$ and polymer level of $45.56 \%$ while percentage elongation and average deflection were minimized with values of $74.12 \%$ and $6.46 \mathrm{~cm}$ respectively.

\section{REFERENCES}

[1] Ahmad, A.A.A., Shamsuddin, S., Aung, L.M., Aminudin, B.A. (2015), investigation of plasticinjection moulding process optimization in complex shape product. Applied mechanics and materials, 695(2015), pp. 260-264

[2] József, G. K; Tibor B (2005). Influence of mold properties on the quality of injection molded parts, Periodica Polytechnica Ser. Mech. Eng. Vol. 49, No. 2, Pp. 115-122

[3] Chunping, D., Changing Y. and Cheng Z., (2007). Theoretical modeling of bonding characteristics and performance of wood composites: part 1.inter -element contact.Journal of wood and fiber science, vol.39, pp.48-55.

[4] Osarenmwinda, J.O, and Nwachukwu J.C. (2010). Development of Composite Material from Agricultural Waste'.International Journal of Engineering Research in Africa. Volume 3, PP42-48

[5] Njoku R.E and Obikwelu D.O.N (2008), swelling characteristics and tensile properties of natural fiber reinforced plastic in selected solvents, Nigerian journal of Technology, vol 27, no2

[6] Westerdale, S., kazmer, D. O., Hazen, D. (2008), a comparison of statistical process control (SPC) nand online multivariate analyses (MVA) for injection molding, international polymer processing, vol. 23: issue5 pages $447-458$

[7] Aliyegbenoma C. O, Eki M. U, Ozakpolor M. O, (2020) Modelling and Production of Injection Moulded Polyproplyn Sawdust Composite, International Journal of Scientific Engineering and Applied Science (IJSEAS) - Vol 6, Pp 1-17

[8] Amenaghawon, N. A.; Ogbeide, S. E; Okieimen, C.O (2014).Application of statistical experimental design for the optimisation of dilute sulphuric acid hydrolysis of cassava Bagasse. Acta Polytechnica Hungarica, 11(9), pp. 1-12.

[9] Montgomery, D.C (2005). Design and analysis of experiments, 6th ed., New York: John Wiley \& Sons, Inc

[10] Carley, K..M; Kamneva,, N.Y;. Reminga, J (2004). Response surface methodology. CASOS-center for computational analysis of social and organizational systems technical report, carnegie Mellon University, School of Computer Science, p. 7 